\title{
Synthesis and characterization study of dual phase mixed zinc cobalt ferrite nanoparticles prepared via chemical co-precipitation method
}

\author{
Rohit R. Powar ${ }^{1}$, Ashok B. Gadkari², Pravina B. Piste ${ }^{3}$, Dnyandevo N. Zambare ${ }^{1 *}$ \\ ${ }^{1}$ Department of Chemistry, Kisanveer Mahavidyalaya, Wai 412803, (MS) India \\ ${ }^{2}$ Department of Physics, GKG College, Kolhapur 416012, (MS) India \\ ${ }^{3}$ Department of Chemistry, YCIS, Satara 415001, (MS) India
}

*Corresponding author

DOI: $10.5185 /$ amp 2018/6997

www.vbripress.com/amp

\begin{abstract}
Nanoparticles of Zinc substituted Cobalt ferrite powders having general formula $\mathrm{Zn}_{\mathrm{x}} \mathrm{Co}_{1-\mathrm{x}} \mathrm{Fe}_{2} \mathrm{O}_{4}(\mathrm{x}=0,0.25,0.5,0.75,1.0)$ have been produced by using analytical grade nitrates and hexadecyltrimethylammonium bromide (CTAB) as structure directing reagent via Chemical co-precipitation method. The structure and morphology of prepared polycrystalline ferrite nanoparticles were investigated by X-ray diffraction (XRD), Fourier Transform Infrared Radiation (FTIR) and Scanning electron microscopy (SEM) respectively. Thermogravimetric differential analysis (TG/DTA) technique gives information about ferrite phase formation occurs beyond $450{ }^{\circ} \mathrm{C}$. The XRD analysis confirms the establishment of the cubic spinel structure with the presence of minor secondary phase of $\alpha-\mathrm{Fe}_{2} \mathrm{O}_{3}$ (hematite) at a calcination temperature of $650{ }^{\circ} \mathrm{C}$. The polycrystalline mixed zinc cobalt ferrite nanoparticles showed a dual phase and crystallite size lies in the range 6-11 nm. FE-SEM microstructure shows the nearly spherical polycrystalline nanoparticles with a particle size in between 0.11-0.20 $\mu \mathrm{m}$. The FT-IR spectra display two significant strong absorption bands nearby in the range of $400 \mathrm{~cm}^{-1}$ and $600 \mathrm{~cm}^{-1} \mathrm{on}$ the tetrahedral and octahedral sites respectively. Copyright @ 2018 VBRI Press.
\end{abstract}

Keywords: Chemical synthesis, nanostructures, XRD, FE-SEM.

\section{Introduction}

The polycrystalline ferrite nanoparticles have been interesting materials studied in the earlier decades owed to their uncommon physical, chemical and magnetic properties of nanomaterial with control size, composition and morphology were unlike from the bulk phase properties of materials. Hence researchers are very keen to find the simple, economical and effective method to prepared nanomaterial's having larger surface area. The spinel ferrite fascinates research importance because of their multipurpose practical applications [1]. Ferrite Nanomagnetic material results in numerous applications in heterogeneous catalysis, microelectronic circuits, adsorption, sensors, piezoelectric devices, magnets, magnetic drug delivery [2-8]. Generally, spinel ferrites having $\mathrm{MeB}_{2} \mathrm{O}_{4}$ structure, where $\mathrm{Me}$ is a metal with +2 valence and $\mathrm{B}$ are trivalent ferric $\left(\mathrm{Fe}^{3+}\right)$ cations respectively [9]. Thus unoccupied interstitial sites of large portion were vacant to migrate cations among interstitial sites. The structural, elemental composition and various cations distribution between the tetrahedral (A) and octahedral (B) sites depended on preparation method and sintering temperature. Recently, spinel ferrite nanoparticles were prepared using numerous methods like co-precipitation [10], microwave refluxing [11], reverse micelle method [12], hydrothermal method [13], sol-gel method [14], spray pyrolysis [15], ceramic method [16] etc.

In this paper, we explosion the synthesis, structural and morphological properties of zincsubstituted cobalt ferrite with general formula $\mathrm{Zn}_{\mathrm{x}} \mathrm{Co}_{1}$ ${ }_{x} \mathrm{Fe}_{2} \mathrm{O}_{4}(x=0-1)$. The spinel ferrites were produced via chemical co-precipitation method followed by calcination in the air has several advantages such as simple, good chemical homogeneity and economical method to produce the large quantity of smaller particles and lower sintering temperature as compared to the ceramic method.

\section{Experimental}

Material

Polycrystalline zinc substituted cobalt ferrite nanoparticles were synthesized by using the precursor materials as cobalt nitrate hexahydrate $\left(\mathrm{Co}\left(\mathrm{NO}_{3}\right)_{2} \cdot 6 \mathrm{H}_{2} \mathrm{O}\right)$, Iron nitrate nonahydrate $\left(\mathrm{Fe}\left(\mathrm{NO}_{3}\right)_{3} .9 \mathrm{H}_{2} \mathrm{O}\right)$, zinc nitrate hexahydrate $\left(\mathrm{Zn}\left(\mathrm{NO}_{3}\right)_{2} .6 \mathrm{H}_{2} \mathrm{O}\right), \quad$ n-hexadecyltrimethylammonium bromide (CTAB), $30 \%$ aqueous ammonia etc. All analytical grade chemical were used as received, without further purification. 


\section{Synthesis}

The polycrystalline spinel ferrites $\mathrm{Zn}_{\mathrm{x}} \mathrm{Co}_{1-\mathrm{x}} \mathrm{Fe}_{2} \mathrm{O}_{4}$ $(\mathrm{x}=0.0$ - 1.0) nanoparticles were produced by using a chemical co-precipitation method. Cobalt nitrate, zinc nitrate, iron nitrate and $\mathrm{CTAB}$ were used as precursor materials. An initial molar proportion of salts cobalt nitrate hexahydrate, zinc nitrate hexahydrate, Iron nitrate nonahydrate were dissolved in minimum quantity of deionized water. An aqueous solution of n-hexadecyltrimethylammonium bromide (critical micelle concentration) was mixed with metal nitrate solution and stirred at $35^{\circ} \mathrm{C}$ for $1 \mathrm{~h}$ on a hot plate with slow and constant stirring by using a magnetic stirrer. The mixture was then mixed with $30 \%$ aqueous ammonia solution by dropwise addition to getting a dark brown precipitate of metal hydroxide at $\mathrm{pH}=9-10$. The $\mathrm{pH}$ was maintained by dropwise addition of $0.1 \mathrm{~N}$ Nitric acid $\left(\mathrm{HNO}_{3}\right)$. The precipitate was digested on a hot plate at $80{ }^{\circ} \mathrm{C}$ for $2 \mathrm{~h}$. The precipitate was then filtered and washed with ethanol and deionized water followed by drying at $110{ }^{\circ} \mathrm{C}$ temperature for $24 \mathrm{~h}$ in air. The synthesized powder was milled with acetone in an agate mortar for $1 \mathrm{~h}$. The airdried powder was then pre-sintered into Muffle furnace at $300{ }^{\circ} \mathrm{C}$ for $2 \mathrm{~h}$. Air Cooled powder was again milled in an agate mortar to make the homogenous mixture and finally sintered at $650{ }^{\circ} \mathrm{C}$ for $3 \mathrm{~h}$ into muffle furnace. The powder was cooled in air and milled in an agate mortar to get a floppy powder.

\section{Characterization}

The thermal character of the as-prepared ferrite powder was monitored by TG/DTA (Nietzsche STA 409 TG DSE) instrument with the sample heated from temperature $25^{\circ} \mathrm{C}$ to $1000^{\circ} \mathrm{C}$ under synthetic air at 10 ${ }^{\circ} \mathrm{C} / \mathrm{min}$ heating rate. X-ray powder diffraction investigation was conducted on a PW-1710 Philips Xray diffractometer (XRD) using $\mathrm{Cu} \mathrm{K} \alpha\left(\lambda=1.5406 \mathrm{~A}^{\circ}\right)$ radiation. Fourier-transformed infrared (FT-IR) transmission spectra of samples in the range of 800-400 $\mathrm{cm}^{-1}$ were recorded using Perkin-Elmer spectrum one spectrophotometer. The surface morphology of the samples was observed by scanning electron microscopy (SEM) using the JEOL JSM 6360 model with magnification range $\mathrm{x} 50$ to 100,000 .

\section{Results and discussion}

\section{Thermo-gravimetric analysis}

Thermal behavior and phase formation temperature of spinel ferrites were monitored by thermogravimetricdifferential thermal (TG-DTA) analysis. The asprepared sample $\mathrm{Zn}_{\mathrm{x}} \mathrm{Co}_{1-\mathrm{x}} \mathrm{Fe}_{2} \mathrm{O}_{4} \quad(\mathrm{x}=0.5)$ was investigated by TG-DTA analysis. The Fig. 1 shows an initial weight loss step $(15.48 \%)$ between temperature range $25-180{ }^{\circ} \mathrm{C}$. The second significant weight loss step $(8.08 \%)$ around temperature range in between 210 $-350^{\circ} \mathrm{C}$. No further weight loss was observed beyond $450{ }^{\circ} \mathrm{C}$ and up to $1000{ }^{\circ} \mathrm{C}$. The weight loss due to loss of adsorbed moisture and due to the decomposition of the organic matrix also a conversion of metal hydroxides into metal oxides. On the DTA curve, the main exothermic peak was observed at near $270{ }^{\circ} \mathrm{C}$ suggesting that combustion of the organic matrix. The plateau formed between $450{ }^{\circ} \mathrm{C}$ and $1000{ }^{\circ} \mathrm{C}$ on the TG curve indicates the formation of crystalline ferrite.

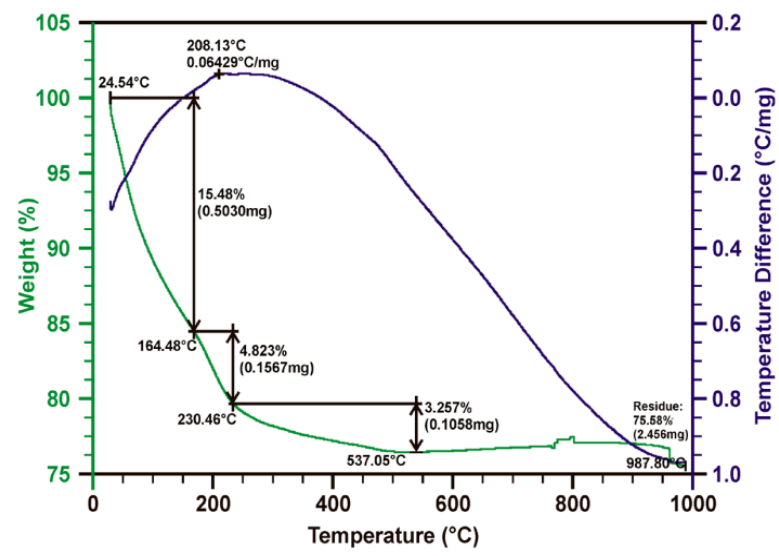

Fig. 1. Thermogravimetric differential analysis curve of as prepared $\mathrm{Zn}_{0.5} \mathrm{Co}_{0.5} \mathrm{Fe}_{2} \mathrm{O}_{4}$.

\section{X-ray diffraction analysis}

The XRD study was done to confirm the structure and secondary phase of the polycrystalline nanoparticles. The XRD pattern of the chemical co-precipitated samples $\mathrm{Zn}_{\mathrm{x}} \mathrm{Co}_{1-\mathrm{x}} \mathrm{Fe}_{2} \mathrm{O}_{4}(x=0,0.25,0.5,0.75$ and 1$)$ were sintered at $650{ }^{\circ} \mathrm{C}$ was shown in Fig 2. The main diffraction peaks were indexed as (220), (311), (222), (400), (422), (511) and (440) which are features of single-phase cubic spinel structure. Peak corresponds to $\alpha-\mathrm{Fe}_{2} \mathrm{O}_{3}$ (hematite) marked as an asterisk (*) were present as a dual phase [17]. The XRD approves the growth of cubic spinel structure in all the samples with minor impurity phase. The X-ray diffraction arrangements agree with JCPDS card number. 77-0011 $\left(\mathrm{ZnFe}_{2} \mathrm{O}_{4}\right)$ [18] and 22-1086 $\left(\mathrm{CoFe}_{2} \mathrm{O}_{4}\right)$ [19].

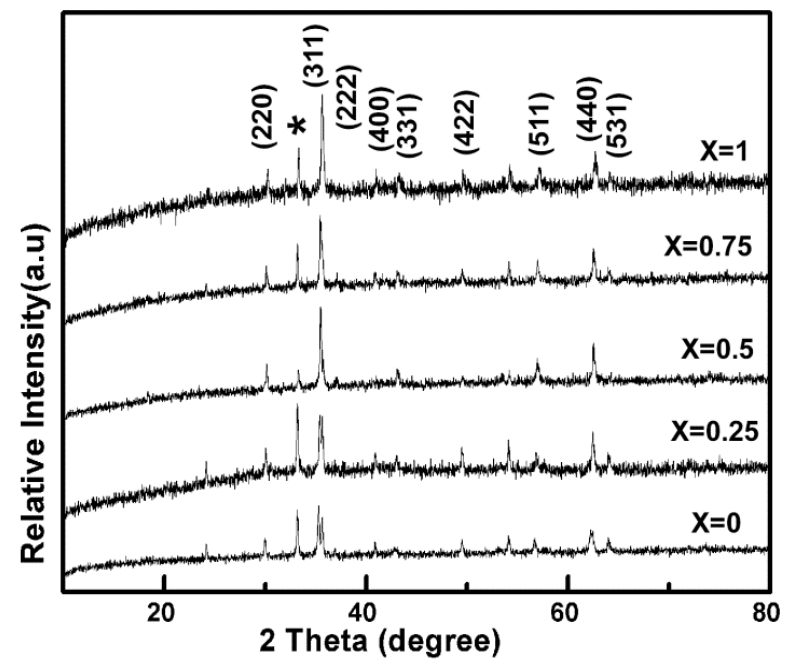

Fig. 2. XRD pattern of $\mathrm{Zn}_{\mathrm{x}} \mathrm{Co}_{1-\mathrm{x}} \mathrm{Fe}_{2} \mathrm{O}_{4}(\mathrm{x}=0,0.25,0.5,0.75$ and 1) Sintered at $650{ }^{\circ} \mathrm{C}$. 
The lattice constant of synthesized polycrystalline ferrites nanomaterial was calculated by using the Bragg's equation [20].

$$
a=d\left(h^{2}+k^{2}+l^{2}\right)^{1 / 2}
$$

where $\mathrm{h}, \mathrm{k}$, and $\mathrm{l}$ are Miller indices of crystal planes. It was apparent that the lattice constant for $\mathrm{Zn}_{\mathrm{x}} \mathrm{Co}_{1-}$ ${ }_{x} \mathrm{Fe}_{2} \mathrm{O}_{4}(x=0,0.25,0.5,0.75$ and 1$)$ samples rises with increasing zinc substitution. This occurs due to the exchange of $\mathrm{Co}^{2+}$ ions with $\mathrm{Zn}^{2+}$ ions. This is also reported by Vaidyanathan et.al. [21]. that lattice constant rises with $\mathrm{Zn}$ concentration. Polycrystalline ferrite samples average crystallite size was calculated by using the Debye- Scherer equation [22].

$$
D=\frac{0.89 \lambda}{\beta \cos \theta}
$$

where $\mathrm{D}$ is the average crystallite size of the ferrite, $\lambda$ is the incident $\mathrm{X}$-ray wavelength of $\mathrm{Cu} \mathrm{K} \alpha$ radiation, $\beta$ is the full-width half maximum (FWHM) in radians in the $2 \theta$ scale and $\theta$ is the Bragg's angle in radian. The average crystallite size and lattice constant of mixed zinc cobalt ferrite were varied with zinc concentration represented in Table 1.

Table 1. Influence of zinc concentration $(\mathrm{x})$ on structural parameters

\begin{tabular}{|c|c|c|c|c|}
\hline \multirow[t]{2}{*}{$\begin{array}{c}\text { Composition } \\
\text { (x) }\end{array}$} & \multirow{2}{*}{$\begin{array}{l}\text { Lattice } \\
\text { constant } \\
\text { 'a' }\left(\mathbf{A}^{0}\right)\end{array}$} & \multirow{2}{*}{$\begin{array}{l}\text { Crystallite } \\
\text { size ' } D \text { ' } \\
(\mathrm{nm})\end{array}$} & \multicolumn{2}{|c|}{$\begin{array}{l}\text { Absorption band } \\
\left(\mathrm{cm}^{-1}\right)\end{array}$} \\
\hline & & & $v_{1}$ & $v_{2}$ \\
\hline 0 & 8.3610 & 6.03 & 545 & 415 \\
\hline 0.25 & 8.3915 & 7.10 & 541 & 418 \\
\hline 0.5 & 8.3958 & 7.89 & 538 & 421 \\
\hline 0.75 & 8.3989 & 9.40 & 525 & 425 \\
\hline 1 & 8.4202 & 10.54 & 520 & 428 \\
\hline
\end{tabular}
of $\mathrm{Zn}_{\mathrm{x}} \mathrm{Co}_{1-\mathrm{x}} \mathrm{Fe}_{2} \mathrm{O}_{4}(0 \leq \mathrm{x} \leq 1)$.

\section{Fourier transformed infrared study}

The FTIR spectrum is one of the methods gives the structural information used to confirm the tetrahedral and octahedral sites of spinel ferrite structure. It also confirms the impurity states and chemical substances adsorbed on the surface of particles. It is observed from Fig. 3 that the FT-IR spectrum shows two characteristics absorption bands in the range $400-800 \mathrm{~cm}^{-1}$ [23]. The higher absorption band wave number $\boldsymbol{v}_{\mathbf{1}}$ and lower absorption band wave number $\boldsymbol{v}_{2}$ observed in the range of $545-520 \mathrm{~cm}^{-1}$ and $415-428 \mathrm{~cm}^{-1}$ respectively. The absorption band at $415 \mathrm{~cm}^{-1}$ was for octahedral sites and $545 \mathrm{~cm}^{-1}$ was for tetrahedral sites of cobalt ferrite spinel structure. The band observed at around $520 \mathrm{~cm}^{-1}$ for $\mathrm{ZnFe}_{2} \mathrm{O}_{4}$ can be assigned to tetrahedral $\mathrm{Zn}^{2+}$ stretching $\boldsymbol{v}_{1}$ and the band observed at $428 \mathrm{~cm}^{-1}$ involves the $\mathrm{Fe}^{3+}$ vibration at the octahedral site v2. Due to the higher weight of zinc, as $\mathrm{Zn}$ concentration increases $\boldsymbol{v}_{\mathbf{1}}$ is decreasing from
$545 \mathrm{~cm}^{-1}$ for $\mathrm{CoFe}_{2} \mathrm{O}_{4}$ to $520 \mathrm{~cm}^{-1}$ for $\mathrm{ZnFe}_{2} \mathrm{O}_{4}$ were depicted in Table 1 [24].

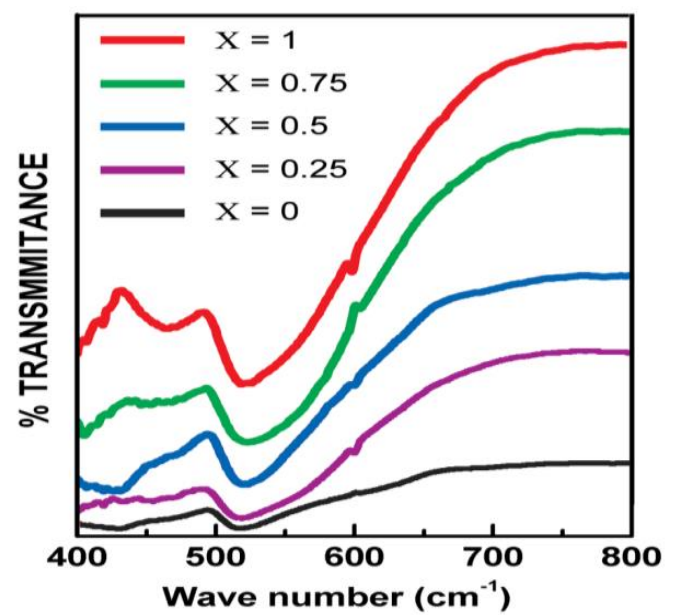

Fig. 3. Infrared absorption spectra of $\mathrm{Zn}_{x} \mathrm{Co}_{1-x} \mathrm{Fe}_{2} \mathrm{O}_{4}(\mathrm{x}=0,0.25$, $0.5,0.75$ and 1$)$.

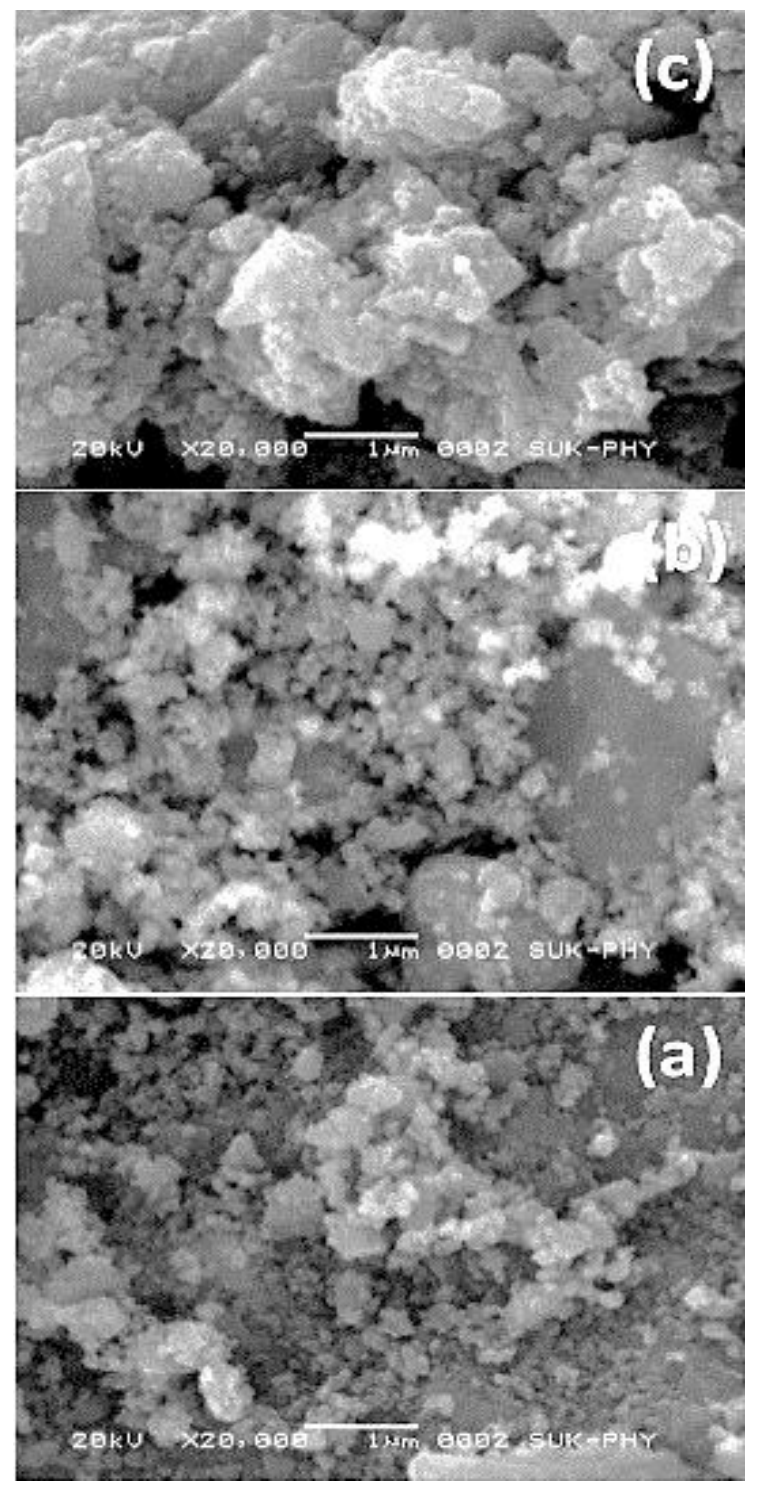

Fig. 4. FE-SEM micrograph of $\mathrm{Zn}_{\mathrm{x}} \mathrm{Co}_{1-\mathrm{x}} \mathrm{Fe}_{2} \mathrm{O}_{4}$ (a) $\mathrm{x}=0$, (b) $\mathrm{x}=0.5$, (c) $\mathrm{x}=1.0$. 


\section{Field-emission scanning electron microscopy study}

FE-SEM micrographs of the samples $\mathrm{Zn}_{\mathrm{x}} \mathrm{Co}_{1-\mathrm{x}} \mathrm{Fe}_{2} \mathrm{O}_{4}$ $\left(\mathrm{x}=0,0.5\right.$ and 1.0) sintered at $650{ }^{\circ} \mathrm{C}$ are shown in Fig. 4. The morphological structures of polycrystalline ferrites with nearly spherical shape and size of the particles are almost uniform and agglomerated. The surface of the ferrite powders shows pores formed by the escaping gases during the sintering of powder. The average grain size in the sample calculated by the linear intercept method [25]. The size of grain ranges from $0.11-0.20 \mu \mathrm{m}$. These particles possess voids and pores which helps to grind and obtain fine particles [26].

\section{Conclusion}

The polycrystalline zinc substituted cobalt ferrite nanoparticles was successfully synthesized via a chemical co-precipitation method. The face-centered cubic spinel structure of $\mathrm{Zn}_{\mathrm{x}} \mathrm{Co}_{1-\mathrm{x}} \mathrm{Fe}_{2} \mathrm{O}_{4}(\mathrm{x}=0.0,0.25$, $0.5,0.75$ and 1) with dual phase of $\alpha-\mathrm{Fe}_{2} \mathrm{O}_{3}$ (hematite) was observed. The thermogravimetric analysis of the as-prepared sample gives information that above $450{ }^{\circ} \mathrm{C}$ the stable phase of mixed zinc cobalt ferrite nanoparticles was obtained. It has been confirmed by the XRD analysis that impurity phase still present in all spinel ferrite sample sintered at $650{ }^{\circ} \mathrm{C}$ and therefore single cubic spinel phase will be formed at the higher sintering temperature. FT-IR confirms two absorption bands in the range of $400-600 \mathrm{~cm}^{-1}$. The scanning electron micrograph revealed that all samples were porous network powder and nearly spherical structure.

\section{References}

1. Sugimoto, M.; J. Am. Ceram. Sco., 1999, 82, 269.

2. P.P. Hankare.; P.D. Kamble; S.P. Maradur; M.R. Kadam.; U.B. Sankpal.; K.P. Patil.; K. Nimat.; P.D. Lokhande.; J. Alloys. Compd, 2009, 487, 730.

3. J. Smit.; Magnetic Properties of Materials; in: Intra University Electronics Series. 1971, 89.

4. Vasambekar, P.N.; Kolekar, C.B.; Vaingankar, A. S.; Mater. Res. Bull. 1999, 34, (6), 863.

5. T, Mathew.; K, Sree Kumar.; B, S, Rao.; C, S, Gopinath.; J. Catal. 2002, 210, 405.

6. Patange, J.M.; Shirsath, S. E.; Lohar, K.S.; Jadhav, S.S.; Mane, D.R.; Jadhav, K.M.; J. Mater. Lett.; 2010, 64(6), 722.

7. M. H, Sousa.; F. Atourinho.; J. Depeyrot.; G. J. da Silva.; M. C. Lara.; J. Phys. Chem. B.; 2001, 105, 1168.

8. Sudimack, J, B, A.; Lee, R, J.; Adv. Drug. Deliv. Rev.; 2000, 41, 147.

9. J. Smith.; H. P. J. Wijin.; Ferrite. John Wiley and Sons, New York 1999.

10. A.B, Gadkari.; T.J. Shinde.; P.N. Vasambekar.; J. of Alloys and Compounds, 2011, 509, 966.

11. J. Giri., T. Sriharsha.; D. Bhadur.; J. Mater. Chem. 2004, 14, 875.

12. V. L. Calero-Ddelc, C.; Rinaldi.; J. Magn. Magn. Mater. 2007, 314,60 .

13. K, Madhusudan, Reddy.; L, Satyanarayana.; Sunkara, V, Manorama.; R. D. K. Misra.; Materials Research Bulletin. 2004, 39, 1491.

14. P. P. Hankare.; K.R. Sandi.; K.M. Garadkar.; D.R. Patil.; I. S. Mulla.; J.Alloys Compd. 2013, 553, 383.

15. S.Z. Zhang.; G.L. Messing.; J. Am. Ceram. Soc. 1990, 73, 61.
16. S.P. Dalwai.; A.B. Gadkari.; T.J. Shinde.; P.N. Vasambekar.; Adv. Mat. Lett. 2013, 4(7), 586.

17. E. R. Kumar.; P. S. Prasada Reddy.; G.S. Devi.; S. Sathiyaraj.; J. Magn. Mag. Mater. 2016, 398, 281.

18 R. Rameshbabu.; R. Ramesh.; S. Kanagesan.; A. Karthigeyan.; S. Ponnusamy.; J Mater Sci: Mater Electron, 2014, 25, 2583.

19. M. Mozaffari.; S. Manouchehri.; M. H. Yousefi.; J, Amighian.; J. Magn. Magn. Mater. 2010, 322, 383.

20. B.D. Cullity.; Elements of X-ray diffraction, Addison Wesley Pub Co INC, 1956.

21. R. Arulmurugan.; B. Jeyadevan.; G. Vaidyanathan.; S. Sendhilnathan.; J. Magn. Magn. Mater., 2005, 288, 470.

22. Lawrence, Kumar; Manoranjan, Kar.; Ceramic international. 2012, 38, 4771.

23. R.D. Waldron.; Infrared spectra offerrites, Phys. Rev. 1955, 99 , 1727.

24. F. Gozuak.; Y. Koseoglu.; A. Baykal.; H. Kavas.; J. Magn. Magn. Mater. 2009, 321, 2170.

25. J.C. Warst.; J.A. Nelson.; J. Am. Ceram. Soc. 1972, 55, 109.

26. Y. Zhang.; G.C. Stangle.; J. Mater. Res. 1994, 9, 1997. 